\title{
A CUNHAGEM DE UM MONARCA: MOEDAS COM A IMAGEM DE ALEXANDRE, O GRANDE
}

The coinage of a monarch: coins with the image of Alexander the Great

La acuñación de un monarca: monedas con la imagen de Alejandro Magno

Thiago do Amaral Biazotto ${ }^{1}$

\section{RESUMO}

Este artigo tem por objetivo apresentar algumas moedas cunhadas com a imagem de Alexandre, o Grande (356-323 a.C.), juntamente com uma discussão teórica acerca do papel das moedas como documento histórico e arqueológico, especialmente em termos de legitimidade de poder representados pela imagem desse monarca nos reversos monetários.

Palavras-Chave: Alexandre, o Grande (356-323 a.C.), Moedas, Poder

\section{ABSTRACT}

This article aims to show some coins minted with the image of Alexander the Great (356-323 B.C.), alongside with a theoretical discussion about the role of coins as historical and archeological documents, especially in terms of legitimacy of power represented by the image of this monarch in the monetary reverses.

Keywords: Alexander the Great (356-323 B.C.), Coins, Power

\section{RESUMEN}

Este artículo tiene por finalidad presentar algunas monedas con la efigie de Alejandro Magno (356-323 aC), unido con una discusión teórica acerca del papel de las monedas como documento histórico y arqueológico, especialmente en términos de legitimidad de poder representada por la imagen de este monarca en los reversos monetários.

Palabras clave: Alejandro Magno (356-323 aC), Monedas, Poder.

\section{O estudo das moedas e o tesouro numismático como fonte}

\begin{abstract}
A moeda é um objeto palpável [...]. Nela pode-se contemplar o busto do soberano, enquanto os reversos mostram suas virtudes e a prosperidade da época [...]. Fazendo parte assim da máquina estatal, onde a numismática entra como um monumento de legitimação do Estado, uma tentativa de manter inalterado o status quo (CARLAN, 2010: 12).
\end{abstract}

\footnotetext{
${ }^{1}$ Mestrando em História pela Unicamp. À época de redação deste artigo, o autor ainda estava na graduação em História pela Unicamp. E-mail: thiago_a_b@yahoo.com.br.
} 
$\mathrm{O}$ interesse pelas moedas data de tempos imemoriais, mas foi apenas a partir da Modernidade que seu estudo passou a ser sistemático. Tendo o primeiro passo sido dado pelo humanista francês Guillaume Budé (1467-1540), graças a seu estudo sobre os sistemas monetários antigos, a numismática - de raiz etimológica ligada ao termo latino nummus (moeda) e que se refere tanto ao estudo destes artefatos quanto ao das medalhas - se fortaleceu desfrutando do status de ciência no final do século XVIII e início do XIX. (CARLAN \& FUNARI, 2012: 17).

Até o século XIX, parece ser crível asseverar que a numismática ainda era vista como disciplina auxiliar da História e sua função primordial era ratificar aquilo que se encontrava na documentação escrita - como a datação de reinados pautada em cunhagens que possuíam a imagem de determinado monarca, por exemplo - numa relação simbiótica com a História Política. (CARLAN, 2010: 24). Também merecem menção os pontos de contato com a História de Arte, usando das representações no material monetário como instrumento de análise de estilos que eram conhecidos por meio das fontes escritas (CARLAN, 2010: 24). Nos séculos seguintes, contudo, a numismática passou a desfrutar de maior autonomia, admitindo ser possível extrair do numerário informações diversas acerca de um povo ou território, quer sejam ligados à economia, às finanças, à produção artística, ao abastecimento militar e à política, e que podem, algumas vezes, se interconectarem. Profícua ilustração é encontrada no capítulo "Os inimigos de Roma: estratégia e formação militar na Antiguidade Tardia”, de Claudio Carlan, parte integrante da obra História Militar do Mundo Antigo: Volume 1: guerras e identidades, organizada pelos estudiosos Pedro Paulo Funari, Margarida Maria de Carvalho, Claudio Carlan e Érica Cristhyane Morais da Silva. Interpretado como período de alto caráter bélico, a chamada Antiguidade Tardia assistiu a profundas mudanças ocorrerem no interior do exército romano, a começar pela incorporação cada vez mais aguda dos chamados "mercenários bárbaros" a seu regimento. Ato contínuo, houve ampliação do sistema monetário do Império, com peças de alto teor propagandista em benefício do Imperador, de modo a fomentar o soldo dessas novas tropas ${ }^{2}$.

Também parte importante do aspecto da moeda como fonte histórica concerne às informações sobre o metal utilizado em seu fabrico:

O primeiro elemento, o metal usado, informava sobre a riqueza de um povo. Os outros dois elementos - tipo e legenda - diziam algo sobre a arte, ou seja, o maior ou menor aperfeiçoamento técnico usado no fabrico do numerário circulante, sobre o

\footnotetext{
${ }^{2}$ Cf. CARLAN, C. "Os inimigos de Roma: estratégia e formação militar na Antiguidade Tardia" in FUNARI, P. P. A., CARVAlHO, M. M., CARLAN, C., SILVA, E. C. M. (orgs.) 'História Militar do Mundo Antigo: guerras e identidades'. São Paulo, Annablume: 2012.
} 
poder emissor e, sobretudo, sobre a ideologia político-religiosa que lhe dava corpo. (CARLAN \& FUNARI, 2012: 66)

No Brasil, outrossim, o estudo da numismática é ainda incipiente, não obstante possuirmos gigantesco tesouro no Museu Histórico Nacional (CARLAN \& FUNARI, 2012: 78). Uma boa descrição sobre o espaço é a seguinte:

\begin{abstract}
Atualmente o MHN ocupa todo o conjunto arquitetônico da antiga ponta do Calabouço, local onde se encontrava instalado originalmente o Forte de Santiago, construído em 1603, ao qual se acrescentou a Prisão do Calabouço (1693) destinada a escravos faltosos - a Casa do Trem (1762) - depósito do "trem de artilharia", responsável pelo deslocamento interno de armas e munições, o Arsenal de Guerra (1764) e o Quartel do Exército (1835). Foi no portão principal do Museu, durante uma recepção aos veteranos da Guerra dos Canudos (1896 - 1897), que o Marechal Carlos Machado Bittencourt (1840 - 1897), morreu a golpes de punhal, defendendo o presidente Prudente de Morais (1841 - 1902) (CARLAN, 2010: 24)
\end{abstract}

Ademais, o Museu Histórico Nacional comporta o maior tesouro numismático da América Latina, com cerca de 120 mil moedas e medalhas (CARLAN, 2010: 25)

\title{
Os reversos monetários e legitimação do poder
}

As pesquisas hodiernas no âmbito da numismática parecem mais voltadas às representações de autoridades em seus reversos, principalmente em termos de legitimidade de poder, associações dos imperadores com seus antecessores ou divindades diversas, numa relação cada vez mais harmoniosa com a História Cultural. É neste ponto que este texto está aportado, começando com uma discussão acerca dos termos técnicos usados para se nomear as partes de uma moeda, passando pela importância das imagens que aparecem nos reversos monetários e encerrando com estudo de caso de algumas moedas batidas com a efígie de um dos mais insignes conquistadores do Mundo Antigo: Alexandre Magno.

Tratando dos termos técnicos da numismática, Carlan apresenta os seguintes como principais:

\footnotetext{
Anverso, vulgarmente conhecido como "cara", encontramos geralmente o busto do governante ou mandatário. Reverso, lado oposto (coroa), representação mais significativa. Legenda, inscrições encontradas no anverso / reverso. Campo corpo da moeda. Eixo ou Alto Reverso, seguindo o sentido do relógio para diferenciar as peças variantes cunhadas na mesma casa ou casas monetárias diferentes. Exergo ou Linha de Terra, sigla localizada no reverso da moeda (abaixo da representação), indica a casa monetária de origem. Bordo cantos da peça. (CARLAN, 2006: 4, grifos no original).
}

$\mathrm{Na}$ descrição acima, consta que o reverso - popular "coroa" - é a parte mais destacável da moeda. Isso se deve à imensa quantidade de símbolos que dele podem ser 
auferidos. Nele é possível ver, em termos abstratos, o "desenvolvimento de uma sociedade" (CARLAN, 2008: 11): conquistas militares, a religião imposta por um soberano ou uma elite, a importância de uma determinada legião ou agrupamento militar, as características fisionômicas de um monarca, seus títulos, o casamento entre membros da nobreza, fortificações, unificação de territórios, representações dos navios de uma cidade portuária, entre outros (CARLAN, 2008: 11; FARIA, 2011: 86). Atribuía-se aos reversos, ademais, a propriedade mágica de afastar o mal (CARLAN \& FARIA, 2012: 45).

$\mathrm{Na}$ Antiguidade, em particular, também digno de nota é o papel das representações nos reversos como meio de propaganda do poder constituído, de forma a manter o status quo. Tal finalidade fica ainda mais clara quando se recorda a quantidade de analfabetos que existia no Mundo Antigo, o que reforça ainda mais o poder simbólico das imagens:

Na Antiguidade (...) a moeda unificava um território, que estava submetido a um mesmo poder político. Mais do que a língua e religião, era o único instrumento ligado ao poder que permanecia estável. Transmitia uma forte carga propagandista do governo central (...). (CARLAN \& FUNARI, 2012: 78).

As moedas, assim sendo, carregam a mensagem precípua do emissor em seus reversos. Seus símbolos trazem as virtudes do monarca como estadista, político, conquistador, piedoso e representante legítimo do cargo que lhe é conferido. Também se pode ver, nos reversos, a prosperidade de uma era, visando a engrandecer seus feitos e apresentar seus soberanos como distintos e autênticos emissários divinos (CARLAN, 2008: 12). A cunhagem liga-se de modo visceral à máquina do Estado e as moedas, portanto, podem ser consideradas documentos oficiais (DAHMEN, 2007: 3).

Não obstante, é admissível lembrar que as relações entre as moedas e o poder instituído não se limitam à Antiguidade. Mencionemos, de passagem, as peças batidas durante a ditadura do general Francisco Franco (1939-1975), na Espanha, por ocasião do aniversário de seu governo. Em sua espécie de prata no valor de 100 pesetas, elas continham a inscrição FRANCISCO FRANCO CAUDILHO DE ESPAÑA POR LA G(RACIA) DE DÍOS, numa tentativa de usar de apanágios do Mundo Antigo de modo a apresentar seu regime totalitário sob o manto de monarquia divina (FARIA, 2011: 6). 

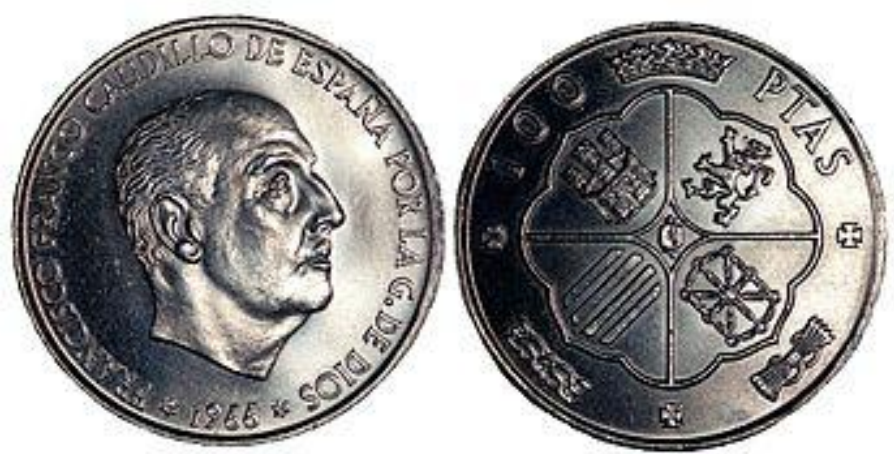

Fig. 1: Moeda de 100 pesetas com a imagem de Francisco Franco. Disponível em: http://upload.wikimedia.org/wikipedia/commons/thumb/a/ab/1970_100_Pesetas.jpg/345px1970 100_Pesetas.jpg (Acesso em 02/02/2013)

De volta ao Mundo Antigo, um caso que parece ser o mais emblemático é o de Alexandre Magno, primeiro monarca a estampar sua imagem no meio circulante (CARLAN \& FARIA, 2012: 3). Seus feitos foram de tal grandeza, que levaram o historiador e político prussiano Johann Gustav Droysen (1808-1884) a criar em sua obra Geschichte Alexanders des Grossen, publicada em 1833, o termo erudito "helenismo" para se referir à cultura nascida do contato entre os greco-macedônios e os autóctones, no período balizado pelas mortes do próprio Alexandre, em 323 a.C., e de Cleópatra, em 30 d.C. Nessa mesma obra, o erudito germânico menciona de maneira breve o papel das moedas nos tempos do conquistador macedônio:

Todas as moedas daquela época que foram conservadas - de ouro, de prata ou de cobre - trazem a efígie de Alexandre. São testemunhas mudas que a ciência moderna conseguiu retirar do mutismo. Comparadas com as peças de ouro e de prata dos reis persas, das inumeráveis cidades gregas e dos reis da Macedônia anteriores a Alexandre, elas oferecem uma informação singular e reveladora (DROYSEN, 2010: 114).

Vimos até aqui a importância da numismática como ciência e o papel dos reversos monetários na legitimação do poder estabelecido. De modo a ilustrar esta demonstração, serão, doravante, apresentadas algumas peças cunhadas com a efígie de Alexandre, atestando como as imagens do monarca visavam a representá-lo como possuidor de ascendência divina e, portanto, que seu poder e conquistas eram de magnitude inabalável.

\section{As faces de um monarca nas cunhagens monetárias}

As cunhagens que retratam Alexandre tornaram-se mais comuns após sua morte, conforme argumenta Darhmen (2007: 6). No entanto, o primeiro exemplo deste artigo é datado de 326-323 a.C., destarte, de quando o conquistador ainda se encontrava em vida. Este 
conjunto de medalhas é denominado de Elephant Medallions ${ }^{3}$, por ilustrarem as campanhas de Alexandre nas Índias, nas quais ele se digladiou com exércitos que dispunham de elefantes em suas fileiras (DARHMEN, 2007: 6). Nessas moedas, o paladino macedônio está trajando uma armadura ao estilo grego e elmo decorado com duas plumas - em consonância com o descrito por Plutarco (Alex. XVI, 7) - numa tentativa de ovacionar os feitos militares frutos da Batalha de Hidaspes, em 326 a.C, travada contra o monarca indiano Poro (DARHMEN, 2007: 110).

As primeiras peças desta série são conhecias desde 1887, quando chegaram ao British Museum, e retratam uma cena da contenda: Alexandre, a cavalo, ataca Poros, que dispõe de um paquiderme como montaria. Contudo, de acordo com as fontes Antigas, o embate entre os líderes jamais ocorreu, uma vez que o filho de Filipe II só encontrou seu desafiante quando a batalha já havia se findado (DARHMEN, 2007: 110). Nos reversos, Alexandre é representado com o relâmpago - elemento característico de Zeus, sua filiação contumaz - e sendo coroado por Nike, a deusa grega da vitória. É clara a volição em apresentá-lo com aura de semi-divindade, ainda que o local de fabrico dessas peças permaneça incerto (DARHMEN, 2007: 6).
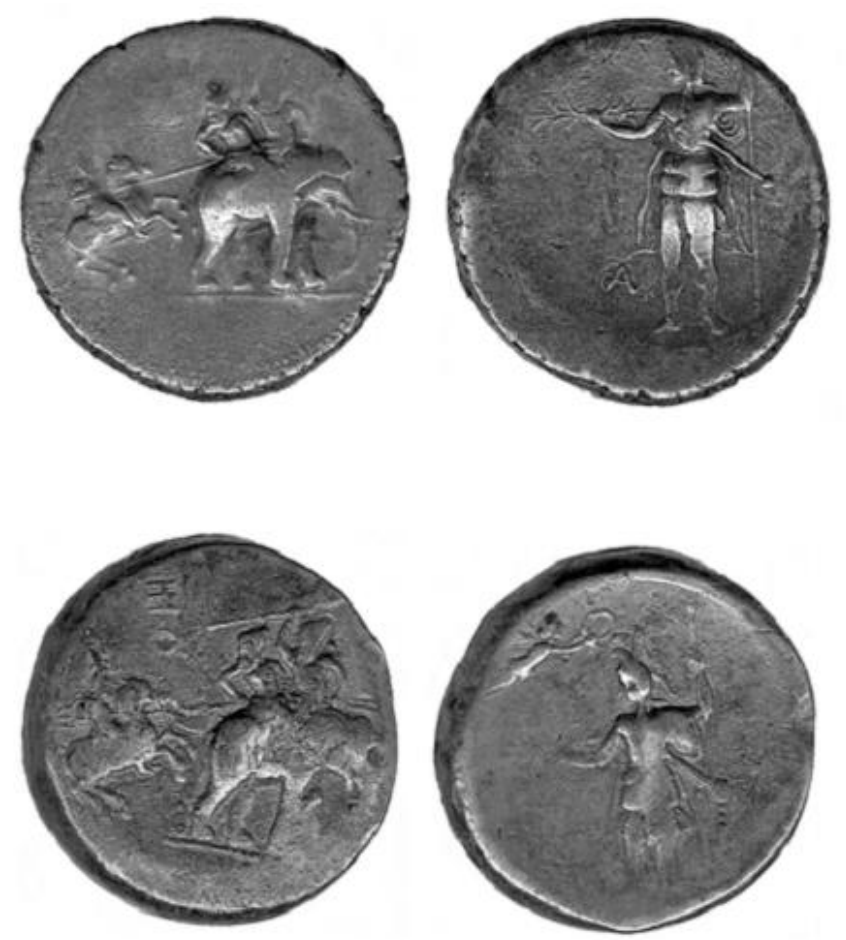

Fig. 2: Os Elephant Medallions. Retirado de DAHMEN (2007: 111).

\footnotetext{
${ }^{3}$ Para uma análise mais pormenorizada desses medalhões: Cf. HOLT, F. Alexander the Great and the mystery of the elephant medallions. University of California Press, Los Angeles: 2003.
} 
Outro exemplo clássico são as peças cunhadas com Alexandre envergando chifres alusivos a Zeus-Amon, moedas que vieram a lume sob Ptolomeu I e persistiram até o período Romano. A peça desta demonstração foi fabricada a mando de Lisímaco (360-281 a.C.), guarda-costas de Alexandre e dos mais conspícuos generais do exército macedônico, no período entre 297-281 a.C. Havia dois tipos principais desta moeda: o primeiro, que será aqui apreciado, continha apenas os chifres, que se curvavam ao redor da orelha do conquistador. Já o segundo, além dos cornos, apresentava um diadema adornando sua cabeça (DAHMEN, 2007: 42).

O filho de Olímpia é representado com chifres de carneiro, animal símbolo do deus egípcio Amon, de maneira a reivindicar uma ascendência dessa divindade. A associação entre conquistador e o deus reporta à visita ao oásis de Siwah, na qual o monarca logra obter o título de faraó, por meio do beneplácito do deus de Karnak, ao mesmo tempo em que mantém sua filiação a Zeus ${ }^{4}$ :

Por ser um deus que servia para unir pessoas de diferentes origens étnicas, ele (Amon) possuía santuários em toda a Grécia e na Macedônia também, além disso, devido à fama do oráculo que resida em Siwah, este deus obteve amplo reconhecimento a ponto do próprio Alexandre o ter escolhido como deidade patrona de sua linhagem. Como Zeus-Amon é uma deidade que soma diferentes deuses, ao mesmo tempo em que cada deus poderia ter uma existência individual, isto possibilitou a Alexandre manter Zeus como deidade de sua linhagem (ALMEIDA, 2007: 26).

No contexto post mortem de Alexandre e a fervilhante disputa entre seus generais pelos territórios de seu imenso império, a cunhagem de peças que continham sua efígie era importante ferramenta de legitimação de poder. Os objetivos de Lisímaco, o comandante da Trácia, ao capitanear a produção desses artefatos podem, assim, ser resumidos da seguinte maneira: "Using Alexander as a figured of his own interests, Lysimachos is able to hide behind Alexander's universal invincibility and finally adopt some of his qualities" (DAHMEN, 2007: 17) ${ }^{5}$.

\footnotetext{
${ }^{4}$ Sobre a visita de Alexandre ao oásis de Siwah, Cf. CARTLEDGE, P. "Leyendas y Legados de Alejandro" in CARTLEDGE, P. Alejandro Magno: la búsqueda de un pasado desconocido. Barcelona: Ariel, 2008

5 "Usando Alexandre como uma representação de seus próprios interesses, Lisímaco está apto a se esconder por trás da invencibilidade universal de Alexander e, finalmente, adotar algumas de suas qualidades”. Tradução do autor.
} 


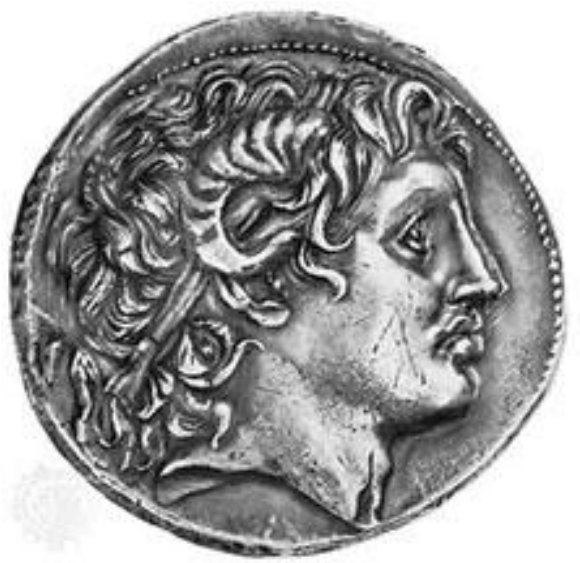

Fig. 3: Tetradracma de prata com a efígie de Alexandre. Retirado de Almeida (2006: 26)

O crescimento da capilaridade da figura de Alexandre fez com que muitos monarcas passassem a bater moedas com sua efígie, de modo a se apresentarem como sucessores lídimos da dinastia do macedônico. Tal era o caso de Agátocles da Báctria, que assumiu o trono por volta de 180 a.C., após disputa com o usurpador Eucrátides, num cenário de intensa necessidade de legitimação de poder (DAHMEN, 2007: 120). Tão logo o comandante bactriano assenhoreou-se da coroa, iniciou a cunhagem de peças que carregavam as seguintes imagens: Zeus, entronado, no reverso, e Alexandre no anverso, no qual se lia a inscrição "Alexandre, filho de Filipe". O reverso também continha a frase "No Reino de Agátocles, o justo". Oportuno ressaltar que este epíteto era auto-atribuído (DAHMEN, 2007: 121).

Dirigindo nossa atenção à forma como Alexandre é apresentado nessa moeda, notase a presença de um escalpo de leão adornando sua cabeça. Se à primeira vista a presença do acessório pode parecer insólita, é oportuno lembrar, por exemplo, da fábula do Leão da Neméia - fera sanguinária - abatida por Hércules, no primeiro de seus dozes trabalhos. De acordo com a lenda, o herói grego deu cabo da besta ao estrangulá-la e, depois, passou a usar de sua pele como manto protetor e de sua cabeça como elmo. Sabe-se que era comum asseverar a ascendência hercúlea em Alexandre, a ponto de Plutarco iniciar sua Vida de Alexandre afirmando que esta filiação era inconteste entre os autores de maior crédito (Alex. II, 2). O ato de extrema destreza, coragem e virilidade de abater um leão com as mãos nuas também foi "herdado" pelo conquistador macedônio, sendo comum em diversas outras representações, de acordo com a interpretação mais corrente ${ }^{6}$.

\footnotetext{
${ }^{6}$ Sobre a alegoria da morte do leão por Alexandre, Cf. PALAGIA, O. "Hephaestion's Pyre and the Royal Hunt for Alexander" in BOSWORTH, A. \& BAYNHAM, E. Alexander the Great in Fact and Fiction. Oxford University Press, 2000.
} 
O objetivo precípuo de Agátocles, era a afirmação de seu poder a partir da invenção de uma linhagem unívoca que se iniciava com Hércules, passava de maneira fundamental por Alexandre, e desembocava no próprio monarca bactriano. Tem-se aqui um exemplo de uso da figura e das lendas em torno do conquistador macedônio (DAHMEN, 2007: 121).
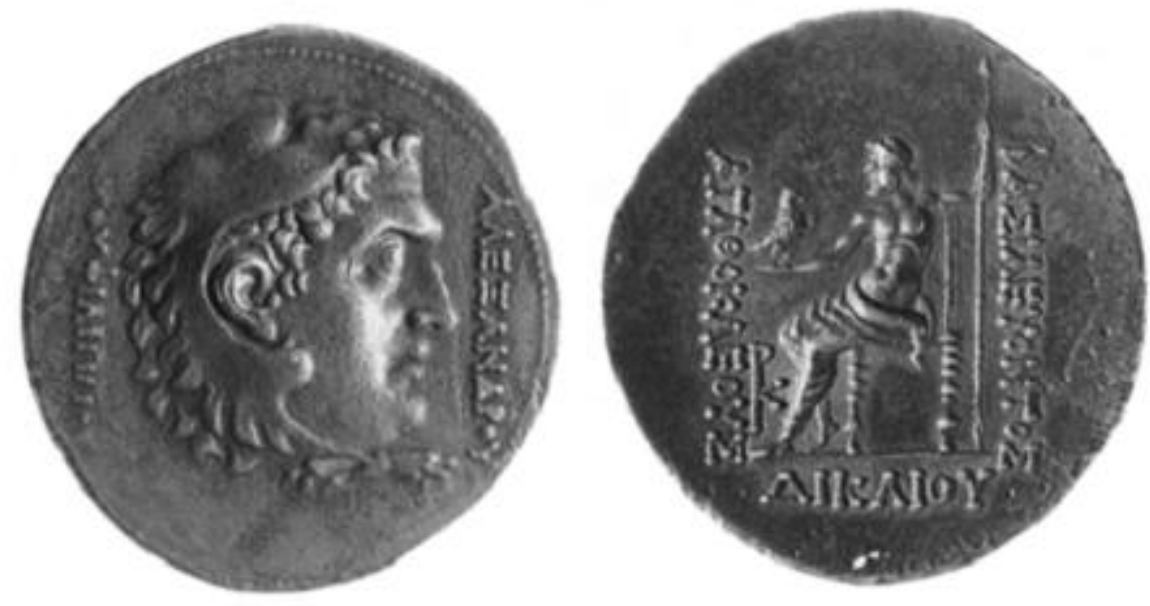

Fig. 4: Tetradracma de Alexandre sob Agátocles. Retirado de (DAHMEN, 2007: 121).

O último exemplo mostra, como defende Jones (1997), que a construção de identidades dá-se de maneira contínua, chegando até os tempos coevos. Trata-se de uma moeda de 100 dracmas que começou a circular na Grécia no ano de 1990. Alexandre aparece com os chifres de Zeus-Amon, já discutidos aqui, com o objetivo claro de se evocar um pretérito glorioso, de se exaltar o caráter altivo de um povo que possui em suas veias o nobre sangue do maior dos conquistadores, de uma nação que - embora em onipresente crise econômica no mundo capitalista hodierno - dispõe de passado frugal que deve ser lembrado e celebrado no presente. Assim como a dimensão de seus feitos e a magnitude de sua lenda, a apropriação da imagem de Alexandre Magno é infinita.
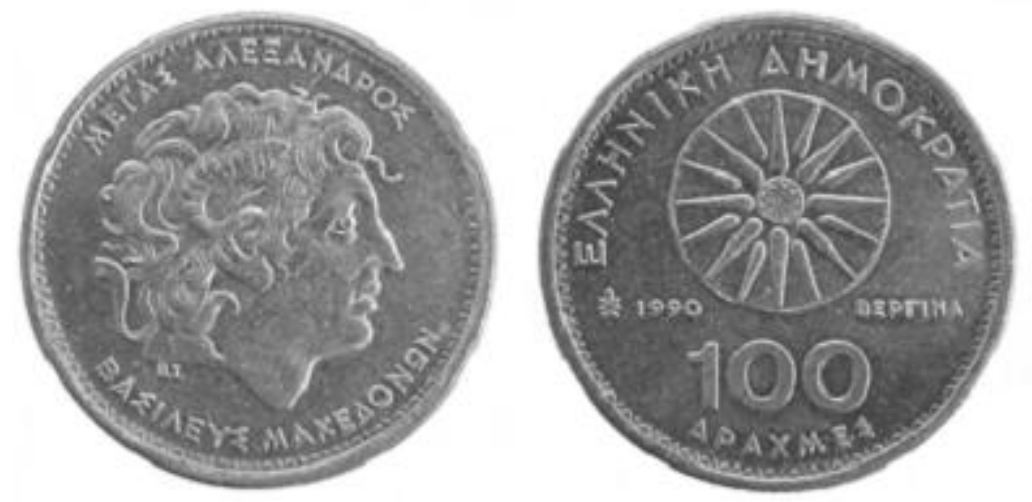

Fig. 5: Moeda de 100 dracmas. Grécia, 1990. Nela, o conquistador é descrito como "Alexandre, o Grande, rei dos macedônios". Tradução da moeda pelo Prof. Dr. Pedro Paulo Funari. Retirado de DAHMEN (2007: 155). 


\section{Considerações finais}

Este artigo teve como objetivo apresentar, de maneira breve e introdutória, o desenvolvimento da numismática como ciência, desde seu surgimento até a atualidade. Se antes ela se encontrava confinada ao auxílio e ratificação dos documentos escritos, agora desfruta de status autônomo, dada a infinidade de informações que se pode extrair do material numerário. Aqui, se buscou refletir nas formas através as quais as representações dos monarcas nos reversos monetários ligam-se às relações de poder, em particular no que concerne à legitimação dos governantes. No que cabe a Alexandre, os exemplos mencionados mostram a louvação dos feitos militares da Batalha de Hidaspes, a tentativa de seus sucessores Lisímaco e Agátocles da Báctria em lastrear seus respectivos reinados por meio da cunhagem de peças que aludiam às façanhas do conquistador e, ademais, como os usos da figura de Alexandre continuam em voga, exemplificado pela moeda batida na Grécia, em 1990.

Esta apreciação de determinadas moedas com a efígie de Alexandre Magno, portanto, espera ter apresentado algumas das muitas formas de se analisar de modo crítico esse pequeno artefato metálico, cuja fascinação que desperta é inversamente proporcional ao seu tamanho.

\section{Referências bibliográficas}

ALMEIDA, A. Ekthéosis Arsinóe: o culto a Arsinóe II Filadelfo. 2007. Dissertação (Mestrado em História). Universidade de São Paulo, São Paulo. 2007.

CARLAN, C. "Os inimigos de Roma: estratégia e formação militar na Antiguidade Tardia" in FUNARI, P. P. A., CARVALHO, M. M., CARLAN, C., SILVA, E. C. M. (orgs) História Militar do Mundo Antigo: guerras e identidades. São Paulo, Annablume: 2012.

CARLAN, C. "Arqueologia e Numismática: A História Antiga e a Cultura Material". Agenda social (UENF), v.4, p. 22-36, 2010.

CARLAN, C. "Arqueologia Clássica e Numismática: o uso das fontes." Boletim da SNB (Sociedade Numismática Brasileira), v. 61, pp 67-75, São Paulo, 2008

CARLAN, C. "Numismática: 'lendo' a moeda como fonte histórica. Um documento alternativo". História e-História, v. 06/03, pp. 1-10, 2006.

CARLAN, C, FARIA, E. "A Política de Alexandre, o grande, e suas representações monetárias." Revista Historiae, v. 2, p. 42-52, 2012. 
CARLAN, C. FUNARI, P. P. A. Moedas: A Numismática e o Estudo da História. São Paulo: Annablume, 2012.

CARTLEDGE, P. Alejandro Magno: la búsqueda de un pasado desconocido. Barcelona: Ariel, 2008

DAHMEN, K. The Legend of Alexander the Great on Greek and Roman Coins. New York: Routledge, 2007.

DROYSEN, J. Alexandre: o grande. Rio de Janeiro, RJ: Contraponto, 2010.

FARIA, E. M. "Alexandre da Macedônia: cunhagens com aspectos de propaganda". Cadernos de Clio, v. 2, p. 85-97, 2011.

HOLT, F. Alexander the Great and the mystery of the elephant medallions. University of California Press, Los Angeles: 2003.

JONES, S. The archaeology of ethnicity: constructing identities in the past and present. London: Routledge, 1997.

PALAGIA, O. "Hephaestion's Pyre and the Royal Hunt for Alexander" in BOSWORTH, A. \& BAYNHAM, E. Alexander the Great in Fact and Fiction. Oxford University Press, 2000.

PLUTARCH. Plutarch lives Demonsthenes and Cicero, Alexander and Caeser. Trad. Bernadotte Perrin. Havard, Harvard University Press, 2004. 